\title{
ARTICLE
}

\section{Eleutheroside B, a selective late sodium current inhibitor, suppresses atrial fibrillation induced by sea anemone toxin II in rabbit hearts}

\author{
Pei-pei Zhang ${ }^{1}$, Zhao-fu Guo ${ }^{1}$, Pei-hua Zhang ${ }^{1}$, Zhi-pei Liu ${ }^{1}$, Lv Song ${ }^{1}$, Ze-fu Zhang ${ }^{1}$, Yu-zhong Jia ${ }^{1}$, Zhen-zhen Cao ${ }^{1}$ and Ji-hua Ma ${ }^{1}$
}

Eleutheroside $B(E B)$ is the main active constituent derived from the Chinese herb Acanthopanax senticosus (AS) that has been reported to possess cardioprotective effects. In this study we investigated the effects of EB on cardiac electrophysiology and its suppression on atrial fibrillation (AF). Whole-cell recording was conducted in isolated rabbit atrial myocytes. The intracellular calcium $\left(\left[\mathrm{Ca}^{2+}\right]_{\mathrm{i}}\right)$ concentration was measured using calcium indicator Fura-2/AM fluorescence. Monophasic action potential (MAP) and electrocardiogram (ECG) synchronous recordings were conducted in Langendorff-perfused rabbit hearts using ECG signal sampling and analysis system. We showed that EB dose-dependently inhibited late sodium current $\left(I_{\mathrm{NaL}}\right)$, transient sodium current $\left(I_{\mathrm{NaT}}\right)$, and sea anemone toxin II (ATX II)-increased $I_{\mathrm{NaL}}$ with $\mathrm{IC}_{50}$ values of 167,1582 , and $181 \mu \mathrm{M}$, respectively. On the other hand, EB $(800 \mu \mathrm{M})$ did not affect L-type calcium current $\left(I_{\mathrm{CaL}}\right)$, inward rectifier potassium channel current $\left(I_{\mathrm{K}}\right)$, and action potential duration (APD). Furthermore, EB $(300 \mu \mathrm{M})$ markedly decreased ATX II-prolonged the APD at $90 \%$ repolarization (APD 90 ) and eliminated ATX IIinduced early afterdepolarizations (EADs), delayed afterdepolarizations (DADs), and triggered activities (TAs). Moreover, EB (200 $\mu$ M) significantly suppressed ATX II-induced $\mathrm{Na}^{+}$-dependent $\left[\mathrm{Ca}^{2+}\right]_{i}$ overload in atrial myocytes. In the Langendorff-perfused rabbit hearts, application of EB $(200 \mu \mathrm{M})$ or TTX $(2 \mu \mathrm{M})$ substantially decreased ATX II-induced incidences of atrial fibrillation (AF), ventricular fibrillation (VF), and heart death. These results suggest that augmented $I_{\mathrm{NaL}}$ alone is sufficient to induce $A F$, and $E B$ exerts anti-AF actions mainly via blocking $I_{\mathrm{NaL}}$, which put forward the basis of pharmacology for new clinical application of EB.

Keywords: eleutheroside B; atrial fibrillation; late sodium current; early afterdepolarization; delayed afterdepolarization; patchclamp techniques

Acta Pharmacologica Sinica (2021) 42:209-217; https://doi.org/10.1038/s41401-020-0453-z

\section{INTRODUCTION}

Atrial fibrillation (AF) causes a huge burden globally, with its high morbidity and mortality, and it is the most common disorder of cardiac rhythm affecting millions of people, especially among the aged population [1, 2]. Presently, the incidence of ventricular arrhythmias is less than that of atrial arrhythmias. To the best of our knowledge, antiarrhythmic agents for rate and/or rhythm control remain the preferred choice for AF under limited treatment options, although catheter ablation has been in clinical use. Hence, investigations on the development of novel drugs against $A F$ treatment are considered prospective and are urgently needed.

Eleutheroside $B$ (EB, also called syringin; $\mathrm{C}_{17} \mathrm{H}_{24} \mathrm{O}_{9}, M_{\mathrm{W}}=$ 372.37), which is the main bioactive constituent derived from the dietetic herb Acanthopanax senticosus (AS) known as Siberian ginseng, is used to treat a variety of diseases in traditional Chinese medicine [3]. EB has been widely reported to possess various pharmacological activities, including antifatigue [4], anticancer [5], anti-inflammatory [6], antiirradiation [7], and antidiabetic activities $[8,9]$. Moreover, EB also has immunomodulatory actions [10] and neuroprotective effects $[11,12]$. In addition to the effects mentioned above, accumulating research has shown that EB exerts cardioprotective functions, such as defending cardiomyocytes against oxidative stress injury and myocardial structural changes, including myocardial hypertrophy $[13,14]$. EB has also been demonstrated to protect against arrhythmia caused by myocardial ischemia/reperfusion in rats [15], but its antiarrhythmic mechanism has not been clarified.

As far as we know, arrhythmogenesis is mainly due to abnormal electrical activity, which has been determined by multiple transmembrane ionic channel currents. Studies on ionic channel currents are distinctly of great significance in expounding the mechanisms of arrhythmogenesis and the action of antiarrhythmic drugs. However, thus far, no relative study is available on the effects of EB on cardiac ion channels.

Thus, our paper aimed to shed light on this issue by investigating the effects of EB on cardiac ion channels in rabbit atrial myocytes and exploring the underlying mechanisms for its inhibitory effects on AF.

\footnotetext{
${ }^{1}$ Cardiac Electrophysiological Research Laboratory, Medical College, Wuhan University of Science and Technology, Wuhan 430065, China Correspondence: Ji-hua Ma (mjhua@wust.edu.cn)

These authors contributed equally: Pei-pei Zhang, Zhao-fu Guo, Pei-hua Zhang
}

Received: 3 January 2020 Accepted: 1 June 2020

Published online: 1 July 2020 


\section{MATERIALS AND METHODS}

The isolation of cardiac atrial myocytes

All animal use was approved by the Experimental Animal Center of Wuhan University of Science and Technology and was consistent with the procedures and protocols of the Guide for the Care and Use of Laboratory Animals of the National Institutes of Health and regulations on animal experimentation of Hubei, China.

Single cardiac atrial myocytes were isolated from New Zealand white rabbits (1.5-2.2 kg, CDC, Wuhan, China). In brief, rabbits with an intravenous injection of heparin $(2000 \mathrm{U})$ for $15 \mathrm{~min}$ were anaesthetized with sodium pentobarbital $(100 \mathrm{mg} / \mathrm{kg})$. Hearts were excised rapidly and mounted on a Langendorff apparatus via the retrograde aorta followed by calcium-free Tyrode's solution (in $\mathrm{mM}: \mathrm{NaCl} 140, \mathrm{KCl} 5.4, \mathrm{MgCl}_{2} 1.2, \mathrm{NaH}_{2} \mathrm{PO}_{4} 0.33$, glucose 10, and HEPES 10, pH 7.4 with $\mathrm{NaOH}$ ) perfused for 5 min. Then, the perfusate was changed to enzyme-containing Tyrode's solution ( $1 \mathrm{mg} / \mathrm{mL}$ collagenase type I; $1 \mathrm{mg} / \mathrm{mL} \mathrm{BSA}$ ) for $\sim 45 \mathrm{~min}$ at $37^{\circ} \mathrm{C}$. Subsequently, the perfusate was replaced with KB solution containing (in $\mathrm{mM}$ ): $\mathrm{KOH} 70$, taurine 20 , glutamic acid 50 , $\mathrm{KCl} 40, \mathrm{KH}_{2} \mathrm{PO}_{4} 20, \mathrm{MgSO}_{4}$ 3, EGTA 0.5, glucose 10, and HEPES 10 $(\mathrm{pH} 7.4$ with $\mathrm{KOH})$ to stop digestion of the enzyme. The left atrial tissue was then removed from the heart, gently agitated in KB solution containing BSA $(0.3 \mathrm{mg} / \mathrm{mL})$, and finally filtered through nylon mesh to obtain single dissociated atrial myocytes. The isolated atrial myocytes were kept in KB solution and were used for experiments within 1-8 h. All solutions used above were saturated with oxygen and were kept at $37^{\circ} \mathrm{C}$.

\section{Chemicals and reagents}

EB (E-4-3-hydroxyprop-1-enyl-2,6-dimethoxyphenyl- $\beta$ - $D$-glucopyranoside, purity $\geq 98 \%$ ) dissolved in methanol was produced by Beijing Bei'na BioTech. Co. (Beijing, China). Sea anemone toxin II (ATX II) and tetrodotoxin (TTX) were purchased from Alomone Labs (JBP, Israel) and Biosharp (Hefei, China), respectively. BSA and HEPES were obtained from Roche (Basel, Switzerland). $\mathrm{CsCl}$ and EGTA were purchased from Amresco (Solon, OH, USA). Unless otherwise specified, all other chemicals and reagents were purchased from Sigma-Aldrich (St. Louis, MO, USA).

\section{Electrophysiological measurements}

Transmembrane current recording. Atrial myocytes were transferred into a small cell chamber with a capacity of $1 \mathrm{~mL}$ and were mounted on the stage of an inverted microscope for $\sim 5$ min until the cells adhered to the wall. Next, the perfusate was replaced with an oxygen-saturated bath solution at a rate of $2 \mathrm{~mL} / \mathrm{min}$. Only the thin rod-shaped myocytes with clear cross striations were chosen for electrophysiological recording. We used microelectrodes with a resistance of $1.5-2.5 \mathrm{M} \Omega$ pulled by a two-step vertical puller (PP-830, Narishige Group, Japan) after being filled with pipette solution for current recordings. Electrophysiological signals of the cardiac myocytes were measured by using an EPC10 amplifier (HEKA Electronic, Germany) and then stored for further analysis. Low-pass filters were set at $2 \mathrm{kHz}$ and digitized at $10 \mathrm{kHz}$ in all recordings. Normalized currents were expressed as the current density in $\mathrm{pA} / \mathrm{pF}$. The capacitance and series resistances were compensated to $60 \%-80 \%$ without electric oscillation. All experiments were performed at room temperature $\left(22 \pm 2{ }^{\circ} \mathrm{C}\right)$.

Transient sodium current $\left(I_{\mathrm{NaT}}\right)$ and late sodium current $\left(I_{\mathrm{NaL}}\right)$ were elicited from the holding potential (HP) of $-90 \mathrm{mV}$, followed by a $300 \mathrm{~ms}$ test pulse at -20 and $-30 \mathrm{mV}$, respectively. The magnitude of the $I_{\mathrm{NaL}}$ current was estimated at $200 \mathrm{~ms}$ of depolarizing pulse. An L-type calcium current $\left(I_{\mathrm{CaL}}\right)$ was generated from an HP of $-40 \mathrm{mV}$ and then given a test pulse of $0 \mathrm{mV}$ for 300 ms. The bath solution of $I_{\mathrm{NaL}}$ and $I_{\mathrm{CaL}}$ contained the following compounds (in mM): $\mathrm{NaCl} 135, \mathrm{CsCl} 5.4, \mathrm{MgCl}_{2} 1.0, \mathrm{BaCl}_{2} 0.3, \mathrm{CaCl}_{2}$ 1.8, glucose $10, \mathrm{NaH}_{2} \mathrm{PO}_{4} 0.33$, and HEPES 10 (pH 7.4 with $\mathrm{NaOH}$ ). In addition, nifedipine $(10 \mu \mathrm{M})$ was used to block calcium currents in $I_{\mathrm{NaL}}$ recordings. The bath solution of $I_{\mathrm{NaT}}$ contained (in $\mathrm{mM}$ ):
$\mathrm{NaCl} 30, \mathrm{CsCl} 105, \mathrm{CaCl}_{2}$ 1.0, glucose 5, $\mathrm{MgCl}_{2}$ 1.0, HEPES 5, and $\mathrm{CdCl}_{2} 0.05$ (pH 7.4 with $\mathrm{CsOH}$ ). The pipette solution for $I_{\mathrm{NaL}}, I_{\mathrm{NaT}}$, and $I_{\mathrm{CaL}}$ contained (in mM): $\mathrm{CsCl} 120, \mathrm{CaCl}_{2} 1, \mathrm{MgCl}_{2}$ 5, $\mathrm{Na}_{2} \mathrm{ATP} 5$, TEA-Cl 10, HEPES 10, and EGTA 10 (pH 7.3 with $\mathrm{CsOH}$ ).

Action potential (AP), recorded from a single atrial myocyte in current clamp mode, was elicited with a $1.5 \times$ threshold intensity of $5 \mathrm{~ms}$ at different cycle lengths, with a 5-s interval between each stimulation pace. Cells were incubated in the abovementioned Tyrode's solution. The pipette solution contained (in $\mathrm{mM}$ ): $\mathrm{KCl} 20$, $\mathrm{MgSO}_{4} 1, \mathrm{Na}_{2}$ ATP 4, Na $\mathrm{NTP}_{3}$ 0.1, K-aspartate 120, and HEPES 10 (pH 7.3 with $\mathrm{KOH})$. Single AP, which was recorded at a stimulation frequency of $1 \mathrm{~Hz}$, required the additional calcium chelating agent EGTA in the pipette solution.

Inward rectifier potassium current $\left(I_{\mathrm{K}}\right)$ was generated from a holding potential of $-40 \mathrm{mV}$ to test potentials of $+50 \mathrm{mV}$, followed by a repolarizing step to $-40 \mathrm{mV}$ for $5 \mathrm{~s}$, with each pulse repeated every $10 \mathrm{~s}$. The external solution was Tyrode's solution with nifedipine $(5 \mu \mathrm{M}), 4$-aminopyridine $(2 \mathrm{mM}), \mathrm{BaCl}_{2}$ $(0.2 \mathrm{mM})$, and $\Pi \mathrm{TX}(1 \mu \mathrm{M})$. The pipette solution contained (in $\mathrm{mM})$ : K-aspartate 120, KCl 30, EGTA 10, HEPES 5, MgATP 4, and $\mathrm{MgCl}_{2} 1$ $(\mathrm{pH} 7.3$ with $\mathrm{KOH})$.

ECG and MAP synchronous recording. The rapidly excised hearts, which were subjected to retrograde cannulation through the aorta using a modified Langendorff apparatus as described above, were abidingly perfused with oxygenated standard Tyrode's solution containing (in $\mathrm{mM}$ ): $\mathrm{NaCl} 137, \mathrm{KCl} 5.4$, HEPES 10, $\mathrm{MgCl}_{2}$ 1.2, $\mathrm{Na}_{2} \mathrm{HPO}_{4} 1.2, \mathrm{CaCl}_{2} 1.8$, and glucose 10 (pH 7.4 with $\mathrm{NaOH}$ ). There were a total of 5 experimental groups as follows: (1) control group: hearts were irrigated with Tyrode's solution throughout the whole recording process; (2) EB-treated group; (3) ATX II-treated group; (4) ATX II + EB-treated group; and (5) ATX II + TTX-treated group. The recording time of monophasic action potential (MAP) and electrocardiogram (ECG) in each heart lasted for $100 \mathrm{~min}$ in all groups. At first, all hearts were perfused with Tyrode's solution until their autonomic rhythm became stable. The perfusates in groups 2 and 3 were changed into Tyrode's solution containing $200 \mu \mathrm{M}$ EB or $7 \mathrm{nM}$ ATX II during the remaining recording time, respectively. The hearts in groups 4 and 5 were recorded for 60 min after the perfusates were replaced with Tyrode's solution containing $7 \mathrm{nM}$ ATX II $+200 \mu \mathrm{M}$ EB or $7 \mathrm{nM}$ ATX II $+2 \mu \mathrm{M}$ TTX, respectively, followed by $7 \mathrm{nM}$ ATX II washing out for the remaining time. All hearts were warmed at $37^{\circ} \mathrm{C}$ during the whole course of recording. AF was defined as the occurrence of rapid irregular atrial rhythms lasting for $300 \mathrm{~ms}$ or more. VF refers to irregular chaotic waves on the ECG rather than orderly ventricular rhythms. Heart death was defined as the disappearance of both ECG and AP during the process of recording. MAP was obtained from the endocardium of the left auricle with a contact electrode. ECG was recorded by using an ECG electrode system. The MAP and ECG signals were monitored simultaneously by a BL-420F biological signal collection and analysis system (Techman, Chengdu Instrument Co., Chengdu, China).

\section{Intracellular calcium $\left(\left[\mathrm{Ca}^{2+}\right]_{\mathrm{i}}\right)$ measurements}

To record the $\left[\mathrm{Ca}^{2+}\right]_{i}$ level, cells were loaded with one of the most common calcium indicators, Fura-2/AM $(1.0 \mu \mathrm{M})$, for $20 \mathrm{~min}$ at the room temperature in the dark, followed by washing before use. First, Fura-2/AM-loaded myocytes with a resting sarcomere length $>1.70 \mu \mathrm{m}$ and no spontaneous contractions were placed in a chamber on an inverted microscope. Second, the cells perfused with oxygen-saturated standard Tyrode's solution at a rate of $2 \mathrm{~mL} / \mathrm{min}$ were recorded stably for $5 \mathrm{~min}$ under field stimulation at a frequency of $1 \mathrm{~Hz}$. All experiments were carried out at $37^{\circ} \mathrm{C}$. The cell shortening and $\left[\mathrm{Ca}^{2+}\right]_{\mathrm{i}}$ transient were recorded synchronously by combining a video edge detector with a television monitor (model IX-70, Olympus, Japan) and a dual-excitation fluorescence photomultiplier system (lonOptix, Milton, MA, USA). Changes in 
a

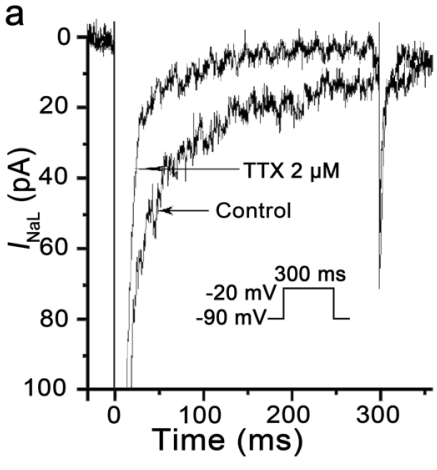

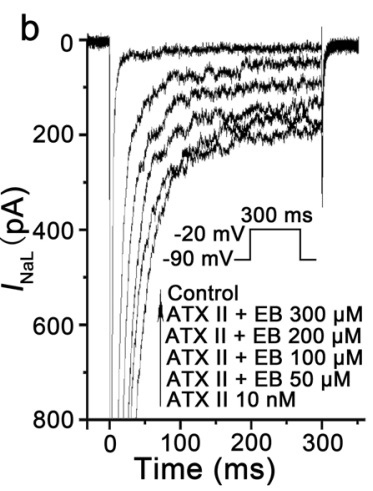

C

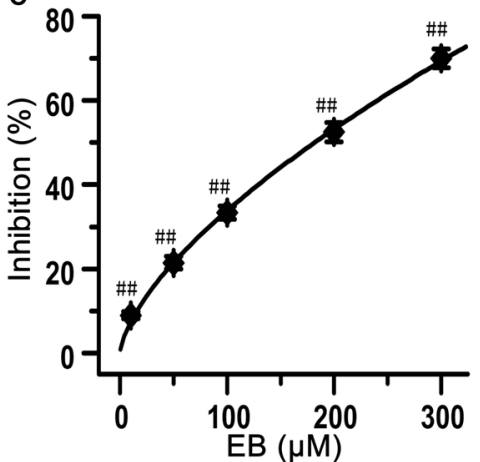

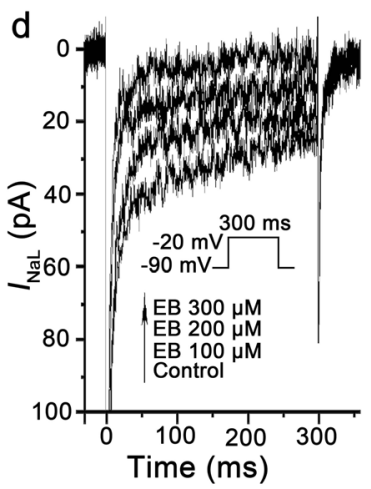

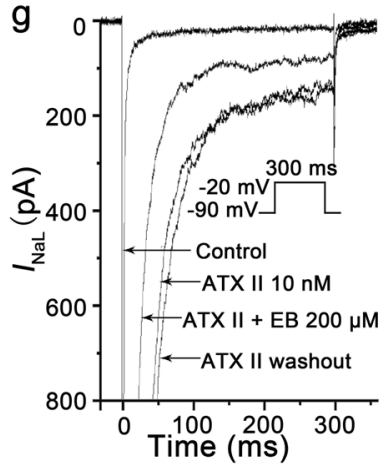

e
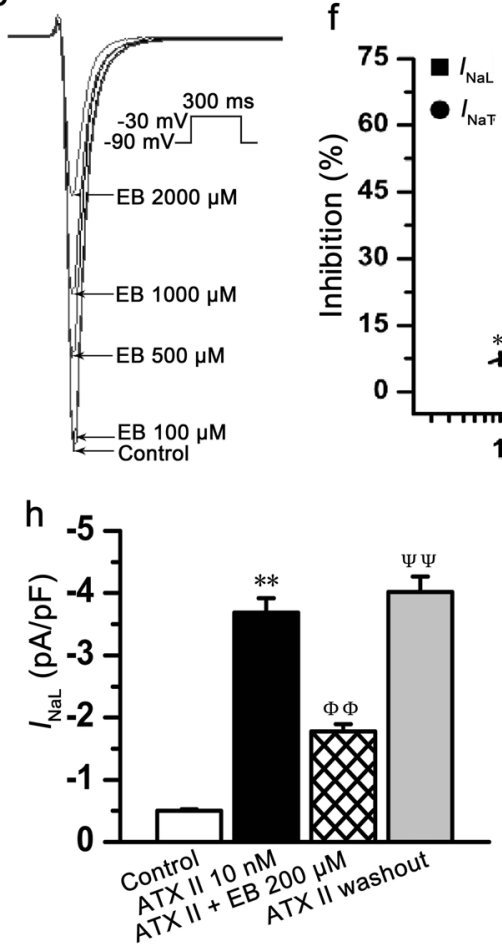

f

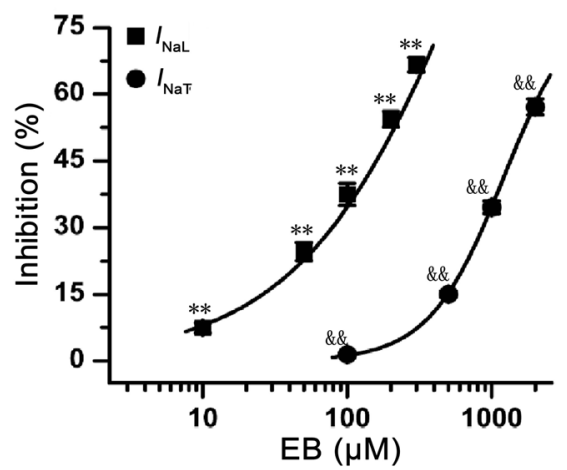

EB $(\mu \mathrm{M})$

Fig. 1 Effects of EB on $I_{\mathrm{NaL}}, I_{\mathrm{NaT}}$, or ATX II-treated $I_{\mathrm{NaL}}$ in atrial myocytes. a Typical current recordings of $I_{\mathrm{NaL}}$ on TTX for the confirmation of $I_{\mathrm{NaL}}(n=7)$. b, c The inhibitory effects of EB on ATX Il-enlarged $I_{\mathrm{NaL}}\left(n=16,{ }^{\#} P<0.01 \mathrm{vs}\right.$. control for all concentrations). d, e Typical current recordings of $I_{\mathrm{NaL}}$ and $I_{\mathrm{NaT}}$ before (control) and after the application of EB at different concentrations in atrial cells. $\mathbf{f}$ The percentage inhibition curves of EB on $I_{\mathrm{NaL}}$ and $I_{\mathrm{NaT}}\left(n=12\right.$ for $I_{\mathrm{NaL}}{ }^{* *} P<0.01$ vs. control; $n=18$ for $I_{\mathrm{NaT}},{ }^{\& \&} P<0.01$ vs. control). g, h Representative traces and histogram showing the inhibitory effect of EB on ATX II-enhanced $I_{\text {NaL }}$ was reversible in atrial cells $\left(n=8,{ }^{* *} P<0.01 \mathrm{vs}\right.$. control; ${ }^{\Phi \Phi} P<0.01 \mathrm{vs}$. ATX II; ${ }^{\Psi \Psi} P<0.01$ vs. ATX II + EB).

$\left[\mathrm{Ca}^{2+}\right]_{\mathrm{i}}$ are presented as the ratio of fluorescence signals $\left(F_{340 \mathrm{~nm}}\right)$ $\left.F_{380 \mathrm{~nm}}\right)$ after subtracting background fluorescence.

Statistical analysis and presentation All values are expressed as individual observations or as the mean \pm SEM of $n$ represented cell counts in each group. Figures were plotted and fitted with Origin 8.0 (Origin Lab Co., Northampton, MA, USA). The incidence of case $=n / N \times 100 \%$, where $n$ is the number of $\mathrm{AF}, \mathrm{VF}$, or heart death cases and $N$ represents the total number of cardiac cases. The concentration-response curves of $I_{\mathrm{NaL}}$ and $I_{\mathrm{NaT}}$ were fitted according to the Hill equation, $Y=B_{\max } /[1$ $\left.+\left(\mathrm{IC}_{50} / D\right)^{n}\right]$, where $B_{\max }$ is the maximum inhibition of the current, $I C_{50}$ is concentration of EB at half-maximum inhibition, $D$ is the concentration of EB, and $n$ represents the Hill coefficient. $Y$, defined as $\left(I_{\text {control }}-I_{\text {drug }}\right) / I_{\text {control, }}$ is the percentage of current inhibited, where $I_{\text {control }}$ and $I_{\text {drug }}$ represent the current amplitudes before and after the treatment with EB, respectively. Data for all statistical analyses were evaluated by using unpaired and/or paired Student's $t$ tests between two groups as appropriate, and repeated one-way ANOVA followed by Tukey's test was applied for multiple group comparisons. The difference considered statistically significant was set at $P$ a value of $<0.05$ or $<0.01$.

\section{RESULTS}

Effects of EB on endogenous $I_{\mathrm{NaL}}, I_{\mathrm{NaT}}$, and ATX II-treated $I_{\mathrm{NaL}}$ in atrial myocytes

In our trials, $I_{\mathrm{NaL}}$ (test voltage at $-20 \mathrm{mV}$ ) was identified by the selective $I_{\text {NaL }}$ blocker TTX (Fig. 1a, b). EB exerted a concentrationdependent inhibitory effect on the amplitude of $I_{\mathrm{NaT}}$ and $I_{\mathrm{NaL}}$, whose $\mathrm{IC}_{50}$ values obtained from the fitted dose-response curves were 1582 and $167 \mu \mathrm{M}$, respectively (Fig. 1C, e). The $\mathrm{IC}_{50}$ ratio of EB on $I_{\mathrm{NaT}}$ and $I_{\mathrm{NaL}}$ was 9.47 ; that is, the inhibitory effect of EB on $I_{\mathrm{NaL}}$ was 9.47-fold more favorable than that on $I_{\mathrm{NaT}}$. In addition, $\mathrm{EB}$ dose-dependently inhibited ATX II-increased $I_{\mathrm{NaL}}$, and the inhibition of $I_{\text {NaL }}$ by EB was reversible after rinsing with ATX II (Fig. 1g-i). 
a

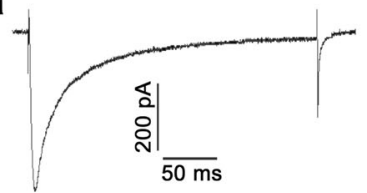

Control

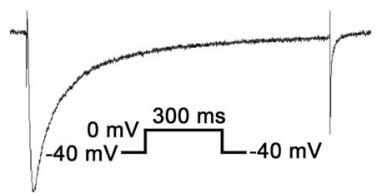

EB $400 \mu \mathrm{M}$

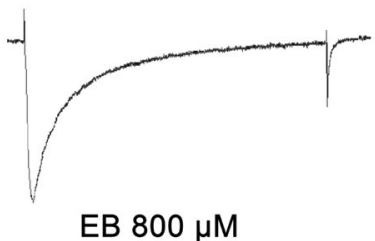

EB $800 \mu \mathrm{M}$

b

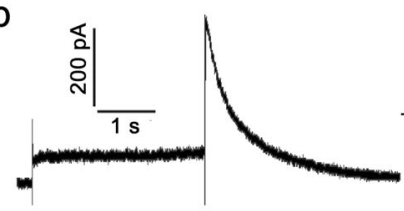

Control

C

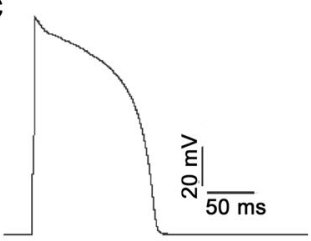

Control

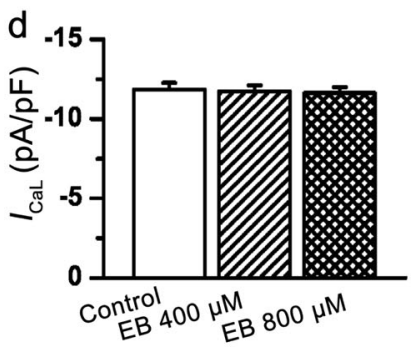

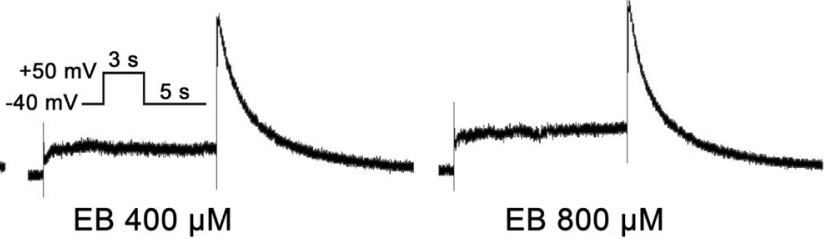

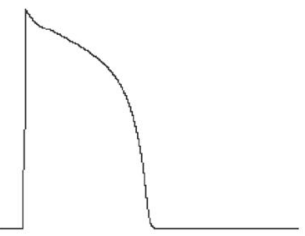

EB $400 \mu \mathrm{M}$

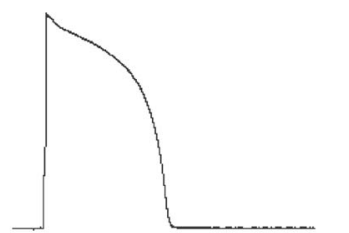

EB $800 \mu \mathrm{M}$
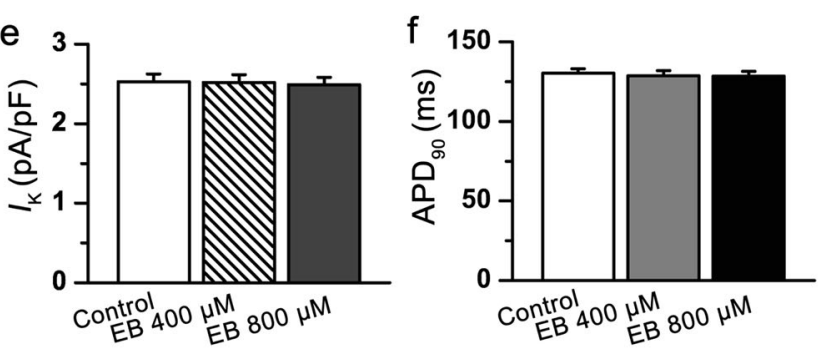

Fig. 2 Effects of EB on $I_{\mathrm{CaL}}, I_{\mathbf{K}}$, and AP in single atrial myocytes. a-c Representative traces of $I_{\mathrm{CaL}}, I_{\mathrm{K}}$, and APs in the absence and presence of EB 400 and $800 \mu \mathrm{M}$, respectively. d-f Histogram showing the inhibitory effects of EB on $I_{\mathrm{CaL}}, I_{\mathrm{K}}$, and APs. Data shown as mean \pm SEM ( $n=12$ for $I_{\mathrm{CaL}} ; n=10$ for $I_{\mathrm{K}} ; n=12$ for AP; $P>0.05$ vs. control for all).

Effects of EB on $I_{\mathrm{CaL}}, I_{\mathrm{K}}$, and AP in atrial myocytes

We further explored the potential effects of EB alone on the $I_{\mathrm{CaL}}, I_{\mathrm{K}}$, and $\mathrm{AP}$, which are closely associated with arrhythmias. Before and after administration of 400 and $800 \mu \mathrm{M} \mathrm{EB}$, EB did not exert noticeable effects on $I_{\text {CaL }}$ (Fig. 2a), $I_{\text {K-tail }}$ (Fig. 2b), or APD 90 (Fig. 2C).

Effects of EB on EADs, DADs, and TAs induced by ATX II in atrial myocytes

In this study, APs were elicited at a frequency of $0.2 \mathrm{~Hz}$. We observed that early afterdepolarization (EAD) appeared first, later followed by the occurrence of afterdepolarization (DAD), and finally, triggering activities (TAs) occurred with passage of time after the application of $5 \mathrm{nM}$ ATX II (Fig. 3a). ATX II not only prolonged the values of $A \mathrm{PD}_{90}$ but also induced EADs and DADs in $18 / 18$ of the tested atrial myocytes, 8 of which were observed to have sustained TAs. EB showed inhibitory effects on the ATX IIprolonged $\mathrm{APD}_{90}$ and eliminated EADs, DADs, and even TAs, which reappeared after a rinse with ATX II (Fig. 3b).

Effects of EB on $\left[\mathrm{Ca}^{2+}\right]_{\mathrm{i}}$ transients induced by ATX II in atrial myocytes

ATX II increased the diastolic $\left[\mathrm{Ca}^{2+}\right]_{\mathrm{i}}$, maximum velocity of $\left[\mathrm{Ca}^{2+}\right]_{\mathrm{i}}$ rise, amplitude of $\left[\mathrm{Ca}^{2+}\right]_{i}$, and maximum velocity of $\left[\mathrm{Ca}^{2+}\right]_{i}$ decay, all of which were distinctly inhibited after exposure to EB (Fig. 4). However, diastolic $\left[\mathrm{Ca}^{2+}\right]_{i}$ increased, but the amplitude of $\left[\mathrm{Ca}^{2+}\right]_{i}$ and the rise and decay velocity of $\left[\mathrm{Ca}^{2+}\right]_{\mathrm{i}}$ transient were inversely reduced after washing out with ATX II alone (Fig. 4b).
Effects of EB on ATX II-induced AF in Langendorff-perfused rabbit hearts

This part of the experiment consisted of five groups as follows: control $(n=3)$; ATX II $(n=11) ; \mathrm{ATX} \mathrm{II+EB}(n=11)$; ATX II + TTX $(n=5)$; and EB $(n=5)$. When the hearts were exposed to ATX II alone, atrial premature beats (APBs) first appeared, followed by frequent $A P B s$, followed by intermittent $A F$, and finally evolved into persistent AF and/or VF (Fig. 5a). In the ATX II group, the number of cases for AF and VF both occurred, AF occurred alone, and heart death was 5, 5, and 7 out of 11 rabbit hearts, respectively. Spontaneous AF appeared after ATX II washout in ATX II + EB and ATX II + TTX group (Figs. 5b, 6a). The number of cases for AF, VF, and heart death were 1,0 , and 1 out of 11 rabbit hearts in the ATX $\mathrm{II}+\mathrm{EB}$ group, respectively. The incidences of spontaneous AF, VF, and heart death were far higher in the ATX II group than in the ATX II + EB group (Fig. 6 b; $91 \%$ vs. $9 \%, P<0.01 ; 45 \%$ vs. $0, P<0.01 ; 64 \%$ vs. $9 \%, P<0.01)$. In addition, spontaneous AF reappeared after washing out with ATX II, and no spontaneous AF, VF. or heart death occurred in the control, ATX II + TTX and EB alone groups.

\section{DISCUSSION}

EB originates from the traditional tonic herb Ciwujia with efficacy for good health and is used extensively in China, Russia, Korea. and Japan [16]. However, the effects of EB on ion channels in atrial myocytes remain unclear. Our study was the first to elaborate this issue and investigate its potential anti-AF mechanisms. The key 
a
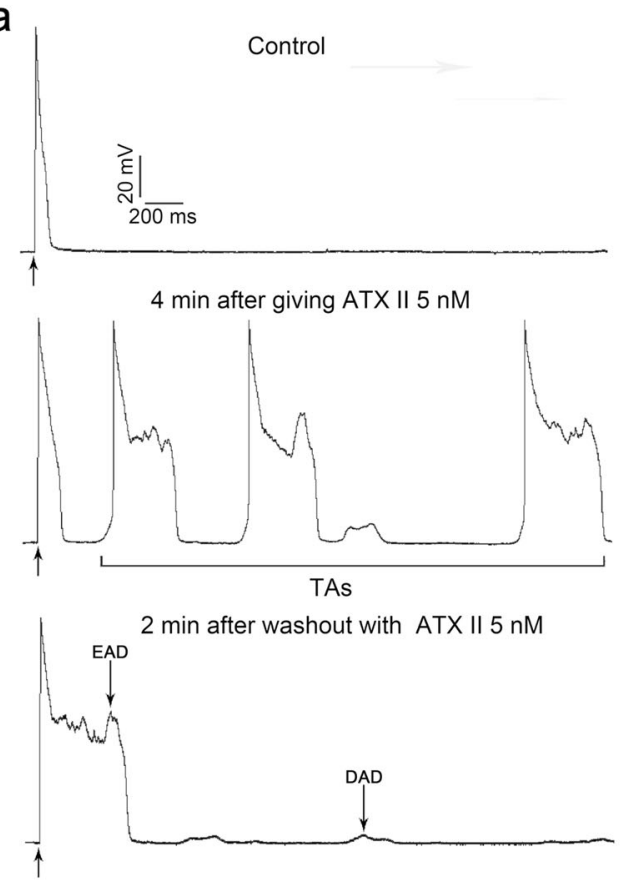

b

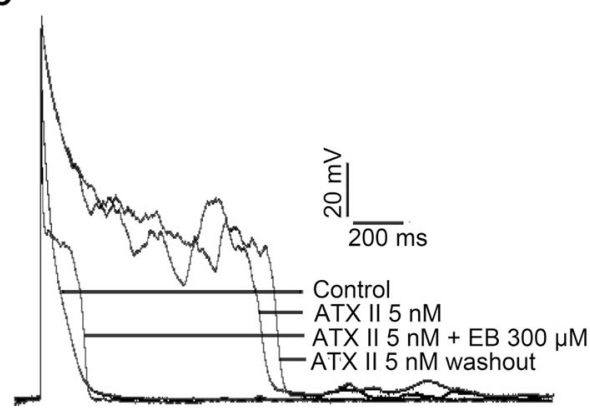

C

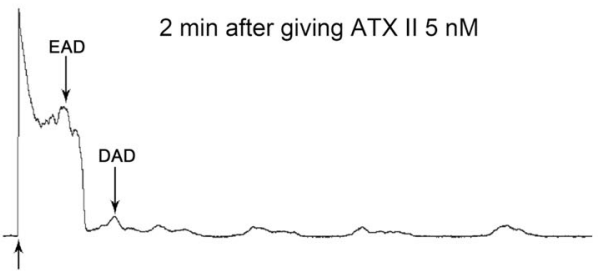

3 min after giving EB $300 \mu \mathrm{M}$
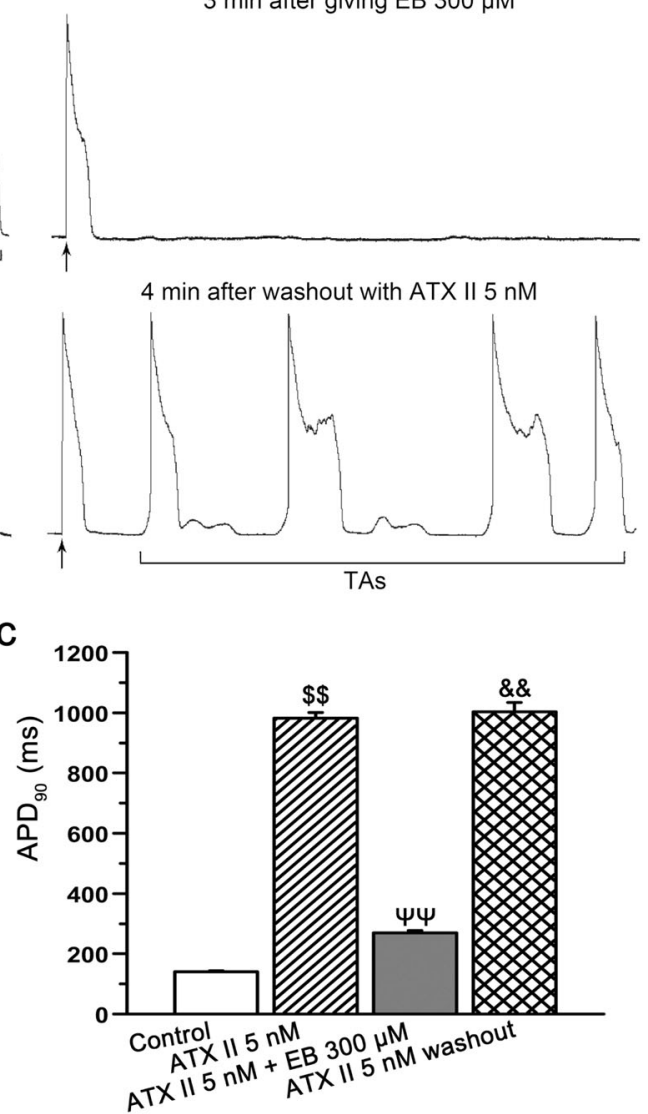

Fig. 3 Effects of EB on EADs, DADs, and TAs of APs induced by ATX II in atrial myocytes (stimuli shown with short arrow). a Time-variant process of representative APs consecutively recorded at a frequency of $0.2 \mathrm{~Hz}$ with application of different drugs. $\mathbf{b}$ The overlay of typical traces of APs showing that EB exerted reversible inhibitory effects on EADs and DADs recorded continuously exposed to different conditions during recording period. c Data of $\mathrm{APD}_{90}$ values shown as mean $\pm \operatorname{SEM}\left(n=18,{ }^{\$ \$} P<0.01\right.$ vs. control; ${ }^{\Psi} P<0.01$ vs. ATX II; ${ }^{\&} P<0.01$ vs. ATX II $+\mathrm{EB})$.

findings of this study showed that EB preferentially inhibited $I_{\mathrm{NaL}}$ far beyond the $I_{\mathrm{NaT}}$, while EB had no inhibitory effects on $I_{\mathrm{CaL}}, I_{\mathrm{K}}$, or AP. In addition, EB concentration-dependently inhibited ATX IIincreased $I_{\mathrm{NaL}}$ in atrial myocytes. Given the abovementioned results, EB provides higher selectivity for $I_{\mathrm{NaL}}$ than the other ion currents, which reveals that EB may have the potential to become a selective $I_{\mathrm{NaL}}$ inhibitor.

$I_{\mathrm{NaL}}$ is a small and persistent inward current in normal hearts, but an elevation in $I_{\mathrm{NaL}}$ exerts proarrhythmic action under pathologic conditions [17]. The $I_{\mathrm{NaL}}$ selective opener ATX II and inhibitor TTX are used as classic drug models in many studies. Observations have shown that $I_{\mathrm{NaL}}$ is enhanced in myocardial cells by various acquired pathological factors, such as myocardial ischemia/hypoxia [18], oxidative stress [19], and especially myocardial structural diseases, including hypertrophic cardiomyopathy [20] and heart failure [21]. Pathologically enlarged $I_{\mathrm{NaL}}$ has been documented to bring about APD prolongation and $\left[\mathrm{Ca}^{2+}\right]_{i}$ overload, finally resulting in arrhythmia [22, 23]. Therefore, inhibition of pathologically enlarged $I_{\mathrm{NaL}}$ exerts prospective antiarrhythmic value. $\mathrm{Na}^{+}$channel inhibitors that are class I antiarrhythmic agents clinically inhibit $I_{\mathrm{NaL}}$ as well as $I_{\mathrm{NaT}}$, which may slow intracardiac excitatory conduction and lead to arrhythmia, thereby even increasing mortality [24]. Due to the drawbacks above, traditional antiarrhythmic drugs that block $I_{\mathrm{NaT}}$ in clinical use are strictly limited, particularly among patients with ischemic heart disease and myocardial infarction [25]. Therefore, it makes a lot of sense to look for selective $I_{\mathrm{NaL}}$ inhibitors with little or no effect on $I_{\mathrm{NaT}}$.

In our present study, we revealed that EB concentrationdependently inhibits $I_{\mathrm{NaT}}$ and $I_{\mathrm{NaL}}$ with a ratio of $I C_{50}$ values of 9.47 ; that is, the inhibitory effect of EB on $I_{\mathrm{NaL}}$ was 9.47 -fold stronger than that on $I_{\mathrm{NaT}}$. However, the $\mathrm{IC}_{50}$ ratios of $I_{\mathrm{NaT}}$ to $I_{\mathrm{NaL}}$ for common class I antiarrhythmic drugs, such as mexiletine, flecainide, disopyramide, and procaine, are 1.91, 1.00, 0.94, and 0.99 , respectively [26]. Ranolazine, whose $\mathrm{IC}_{50}$ ratio of $I_{\mathrm{NaT}}$ to $I_{\mathrm{NaL}}$ is 4.49 in ventricular myocytes, is accepted as a preferred inhibitor of $I_{\mathrm{NaL}}$ in clinical use $[26,27]$. Nevertheless, ranolazine also blocks $I_{\mathrm{Kr}}$ in its therapeutic concentration range, bringing uncertainty and controversy to its safety and efficacy against arrhythmias [28]. In contrast, EB allowed $I_{\mathrm{CaL}}$ and $I_{\mathrm{K}}$ to remain unaffected at a high 
a

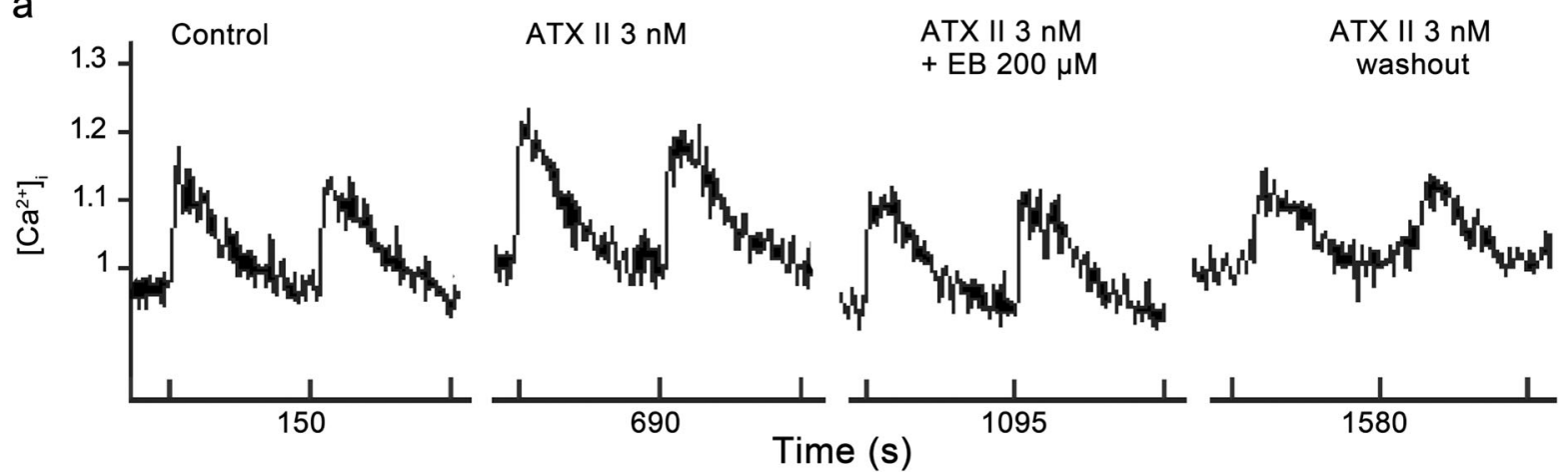

b
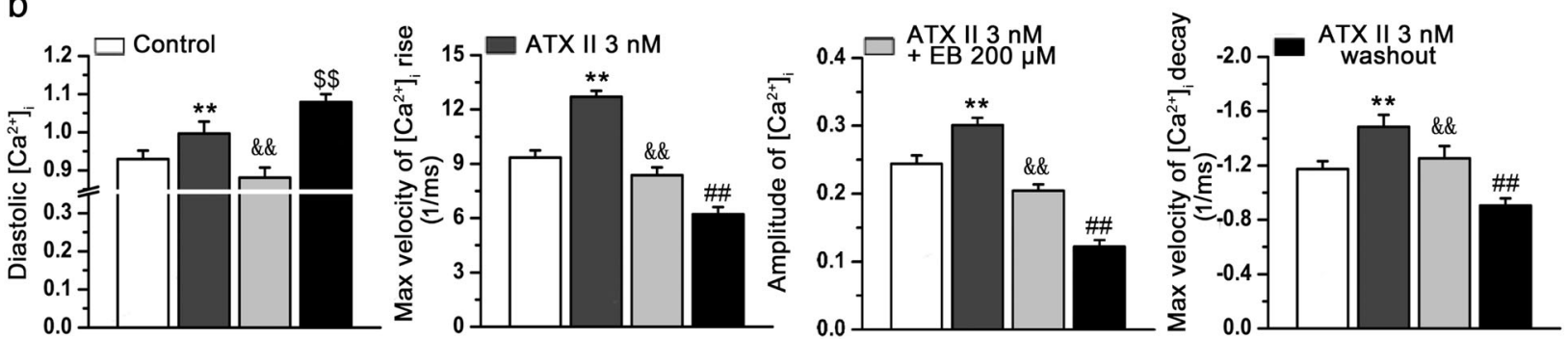

Fig. 4 The effects of EB on ATX II-treated $\left[\mathrm{Ca}^{2+}\right]_{i}$ transient in a single atrial myocyte. a Representative traces of $\left[\mathrm{Ca}{ }^{2+}\right]_{i}$ transients in the presence of different treatments in time scales. Single atrial myocytes were field stimulated at a frequency of $1 \mathrm{~Hz}$. Changes in $\left[\mathrm{Ca}^{2+}\right]_{i}$ are presented as the ratio of fluorescence signals $\left(F_{340 \mathrm{~nm}} / F_{380 \mathrm{~nm}}\right)$ after subtracting background fluorescence. $\mathbf{b}$ The summary data of diastolic $\left[\mathrm{Ca}^{2+}\right]_{\mathrm{i}}$ maximum velocity of $\left[\mathrm{Ca}^{2+}\right]_{i}$ rise, amplitude of $\left[\mathrm{Ca}^{2+}\right]_{i}$, and maximum velocity of $\left[\mathrm{Ca}^{2+}\right]_{i}$ decay were shown as mean $\pm \mathrm{SEM}$ under control conditions, 3 nM ATX II, ATX II $+200 \mu \mathrm{M} \mathrm{EB}$, and ATX II alone washout. $\left(n=14,{ }^{* *} P<0.01\right.$ vs. control for all; ${ }^{\& \&} P<0.01$ vs. ATX II for all; $n=12$, ${ }^{\$ \$} P<$ 0.01 vs. ATX II $+E B ;{ }^{\# \#} P<0.01$ vs. ATX II $\left.+E B\right)$.

concentration $(800 \mu \mathrm{M})$. In particular, no significant inhibition from EB on $I_{\mathrm{K}}$ avoids the accompanying proarrhythmic effects due to $I_{\mathrm{K}^{-}}$ prolonged APD and improves its safety for drug use. These results indicate that EB has the potential to become a more effective and specific $I_{\mathrm{NaL}}$ inhibitor.

Increased $I_{\text {NaL }}$ has a very large impact on the occurrence and development of EADs and DADs, which play crucial roles in triggered arrhythmias. Hence, the $I_{\text {NaL }}$ opener ATX II was employed to induce EADs and DADs in this study. ATX II not only prolonged APD but also induced EADs, DADs, and even TAs, which was in line with previous studies $[29,30]$. On the one hand, the ATX II-enhanced $/$ NaL prolonged APD, which gave enough time to reactivate $I_{\mathrm{CaL}}$, and thus promoted the appearance of EADs [29]. On the other hand, the enhanced $I_{\mathrm{NaL}}$ increased persistent $\mathrm{Na}^{+}$influx, boosting reverse NCX activities and producing $\mathrm{Na}^{+}$-dependent $\left[\mathrm{Ca}^{2+}\right]_{\mathrm{i}}$ overload, which in turn strengthened the forward $\mathrm{NCX}$ activity with $3 \mathrm{Na}^{+}$entering and $1 \mathrm{Ca}^{2+}$ exiting, generating an inward current causing DADs that ultimately evolved into TAs when the cells repolarized to their resting potential [31, 32]. Our results provide evidence that EB not only effectively shortens APD but also eliminates EADs, DADs, and TAs elicited by ATX ॥l by inhibiting $I_{\text {NaL }}$ in atrial cells. The inhibitory effects of EB on $I_{\text {NaL }}$ appeared to play a vital role in its antiarrhythmic action.

Homeostasis in $\left[\mathrm{Ca}^{2+}\right]_{i}$ is of crucial importance to maintain normal physiological functions. Many studies have confirmed that $\left[\mathrm{Ca}^{2+}\right]_{\mathrm{i}}$ overload under pathological conditions can trigger arrhythmias [33]. Therefore, we further explored the effects of $\mathrm{EB}$ and ATX II-enhanced $I_{\mathrm{NaL}}$ on $\mathrm{Ca}^{2+}$ transients in atrial myocytes. In our $\left[\mathrm{Ca}^{2+}\right]_{\mathrm{i}}$ transient experiments, the diastolic $\left[\mathrm{Ca}^{2+}\right]_{\mathrm{i}}$ concentration further increased, indicating that $\left[\mathrm{Ca}^{2+}\right]_{i}$ overload was further aggravated after ATX II washout. The amplitude and rise and decay velocity of $\left[\mathrm{Ca}^{2+}\right]_{i}$ are irreversible, which suggests that the regulation of sarcoplasmic reticulum calcium was disrupted. Given the above, ATX II not only caused $\left[\mathrm{Ca}^{2+}\right]_{\mathrm{i}}$ overload but also ultimately led to $\left[\mathrm{Ca}^{2+}\right]_{\mathrm{i}}$ transient dysfunction during reperfusion treatment with ATX II, which has been proven to participate in arrhythmia in previous studies. More importantly, in our results, EB potently prevented $\mathrm{Na}^{+}$-dependent $\left[\mathrm{Ca}^{2+}\right]_{i}$ overload and sequentially alleviated the imbalance of sarcoplasmic reticulum calcium transport. In short, EB prevented $\left[\mathrm{Ca}^{2+}\right]_{i}$ overload and eventually protected hearts against arrhythmias via inhibition by EB on ATX II-enhanced $I_{\mathrm{NaL}}$, which thus illustrates the underlying mechanism of EB on antiarrhythmia induced by $\mathrm{Ca}^{2+}$ overload in atrial myocytes.

Currently, AF is a commonly encountered atrial arrhythmia in clinical use $[34,35]$. Investigations have shown that the pathologic increase in $I_{\mathrm{NaL}}$ is responsible for the pathogenesis of $\operatorname{AF}[25,36]$. Myocardial ischemia/infarction has been reported to increase $I_{\mathrm{NaL}}$ alone with susceptibility to AF $[37,38]$; thus, we presumed that protection from EB against myocardial ischemia/infarction and AF may correlate to its inhibitory effect on an enlarged $I_{\mathrm{NaL}}$. Therefore, we further investigated the effects of EB on enlarged $I_{\mathrm{NaL}}$-induced atrial arrhythmias in Langendorff-perfused rabbit hearts. In our study, we observed that enlarged $I_{\mathrm{NaL}}$ induced by ATX II individually directly induced spontaneous $A F$, implying an enhancement in $I_{\mathrm{NaL}}$ is an important contributor to AF. We also found that the incidence of ATX II-induced AF (91\%) was apparently higher than that of VF (45\%) in 11 rabbit hearts, and the incidences of $\operatorname{AF}(9 \%, 0)$ and VF $(0,0)$ induced by ATX II were substantially reduced with the application of EB and $T T X$, respectively. In addition, our previous findings showed that the current density of $I_{\mathrm{NaL}}$ is richer in the atria than in the ventricle $[39,40]$. Combined with these research findings, atrial tissues may be more sensitive to ATX II than ventricular tissues; that is, the enhanced $I_{\mathrm{NaL}}$ is more likely to induce AF compared with VF in accordance with our results mentioned above. In addition, the $I_{\mathrm{NaL}}$ inhibitor TTX eliminated spontaneous AF induced by ATX II, indicating that the suppression of $I_{\mathrm{NaL}}$ showed a positive anti-AF effect, which was in accordance with the results obtained from EB under all other identical conditions in our performed experiments. Above all, EB protection of hearts against AF was closely 
a Control

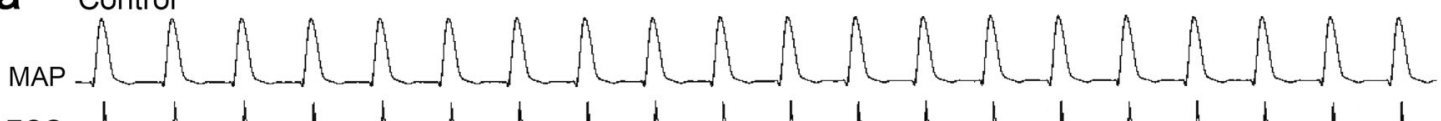

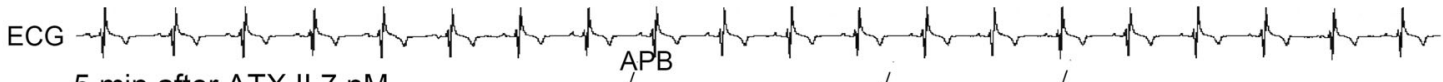
MAP ECG

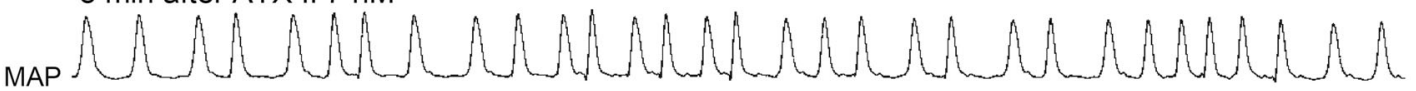

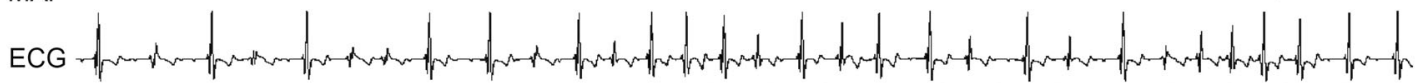
12 min after ATX II $7 \mathrm{nM} \quad \mathrm{AF}$

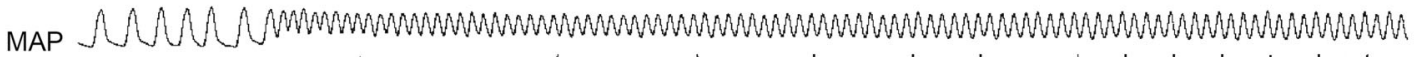

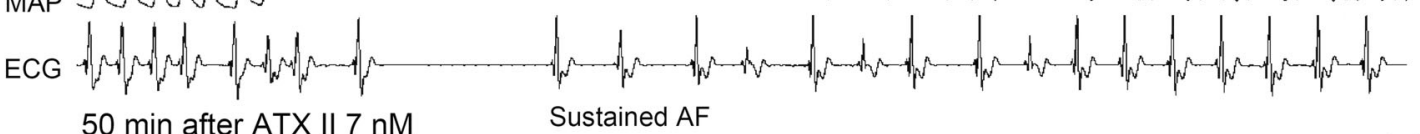

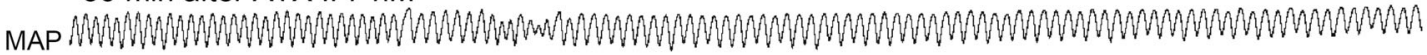

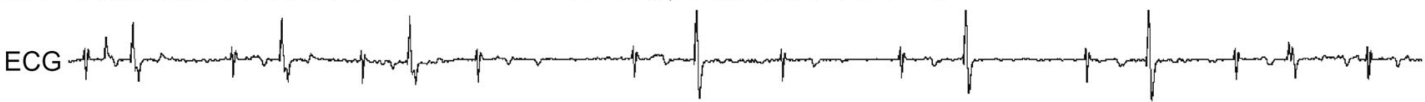

b Control

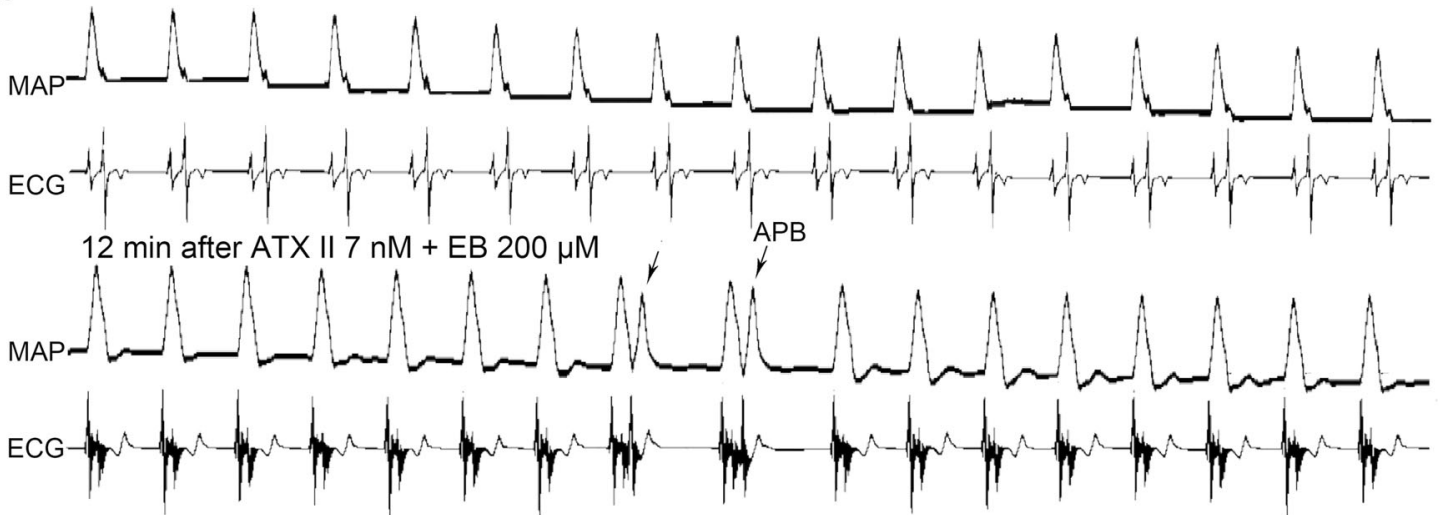

50 min after ATX II 7 nM + EB $200 \mu \mathrm{M}$

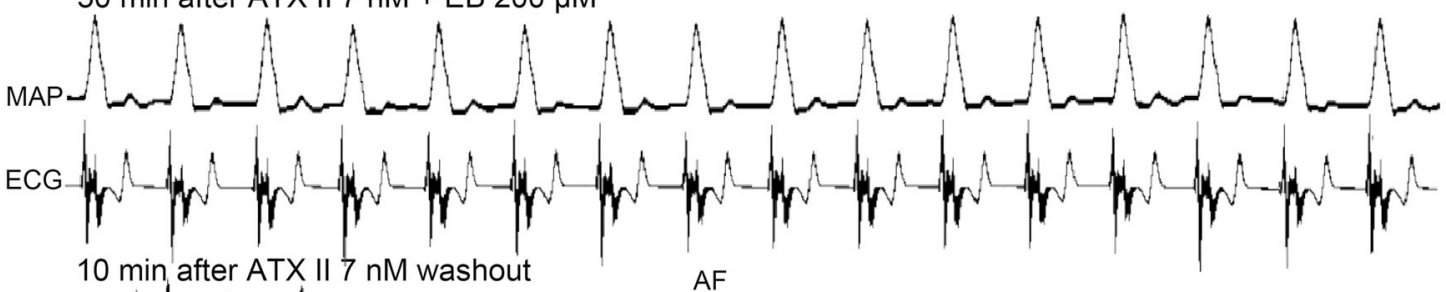

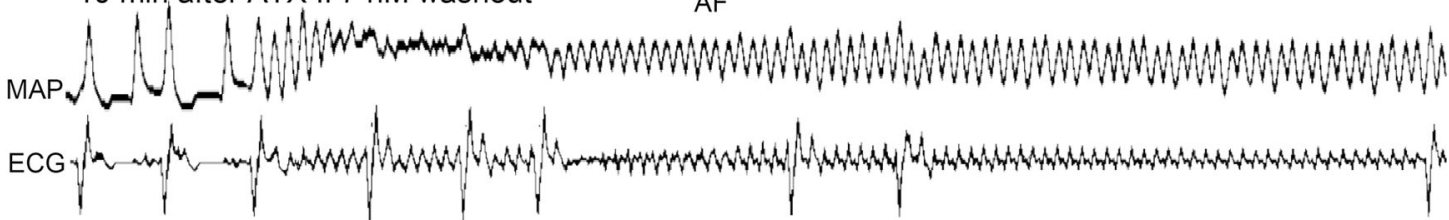

Fig. 5 Effects of EB on ATX II-induced arrhythmias in Langendorf-perfused rabbit hearts (APB represented atrial premature beat). a, $b$ Representative recordings of MAP (upper records in each panel) and ECG (lower records in each panel) recorded synchronously in ATX II group, ATX II + EB group during different period.

associated with its inhibitory effects on $I_{\mathrm{NaL}}$, which might be the basis for its anti-AF action.

At present, EB has not yet been available as a drug in clinical usage, and thus, studies on the variety pharmacological actions of
EB have mainly focused on animal models and human cells. A previous study showed that EB $(100 \mathrm{mg} / \mathrm{kg}$, i.p.) possesses hepatoprotective effects and improves the survival rates of mice with hepatic failure [41]. A recent study reported that EB $(256 \mu \mathrm{M})$ 

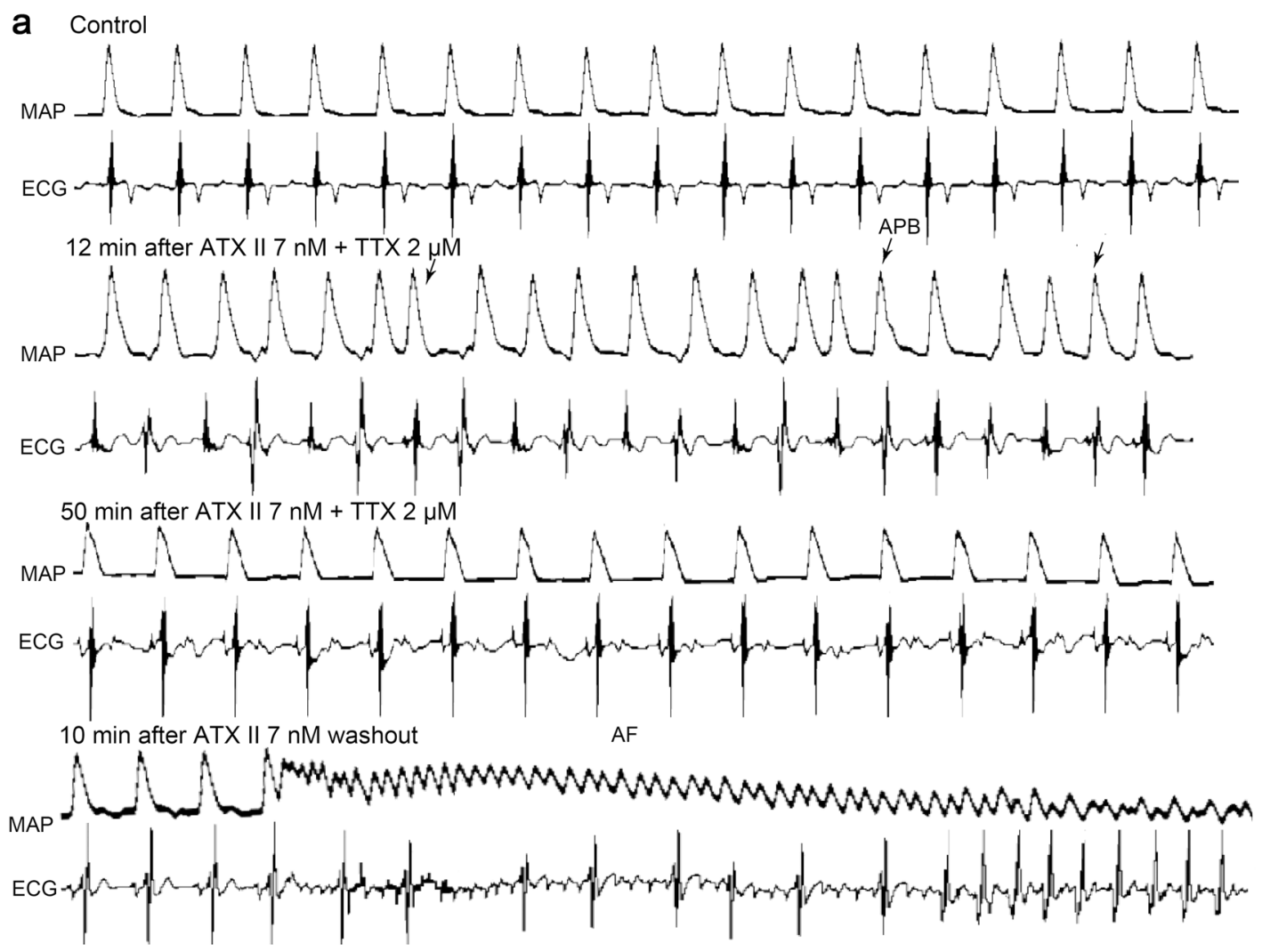

b b1

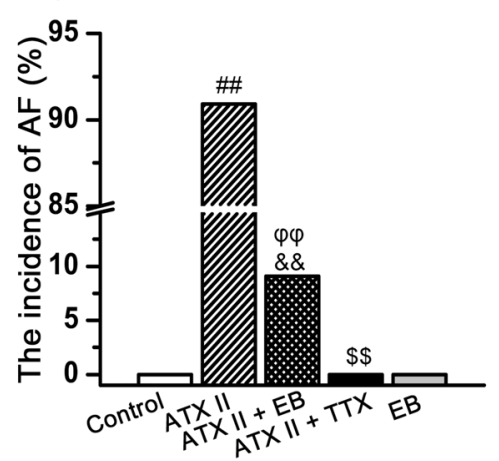

b2

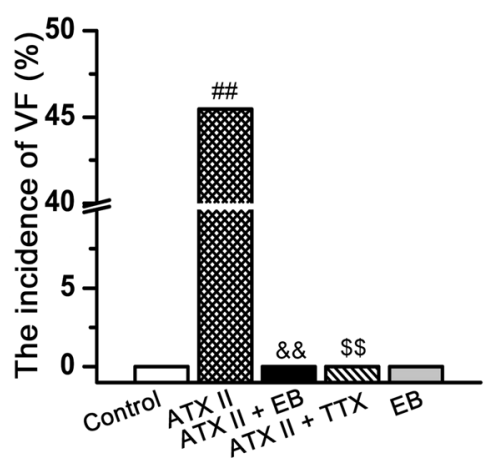

b3

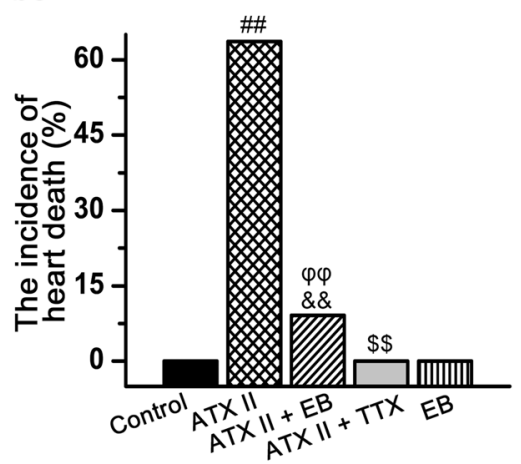

Fig. 6 Effects of TTX on arrhythmias induced by ATX II in Langendorf-perfused rabbit hearts (APB represented atrial premature beat). a Representative recordings of MAP (upper records in each panel) and ECG (lower records in each panel) recorded synchronously in ATX II + TTX group throughout the whole recording period. b The incidences of AF, VF, and heart death in following five groups: control, ATX II, ATX II + EB, ATX II + TTX, EB (Mean \pm SEM. ${ }^{\# \# ~} P<0.01$ vs. control group for all; \&\& $P<0.01$ ATX II + EB vs. ATX II group for all; ${ }^{\varphi \varphi} P<0.01$ ATX II + EB vs. EB group; ${ }^{\$} P<0.01$ ATX II + TTX vs. ATX II group for all).

exerts a protective effect on acute kidney injury with little effect on cell viability in mouse and human kidney-2 cell models [42]. In addition, injections and tablets of Ciwujia as compound Chinese medicines, which have not been reported to have toxic side effects except for causing hypertensive responses, have currently been used in clinical practice in China. Furthermore, EB is the main bioactive ingredient of Ciwujia, serving as one of the most popular herbal dietary supplements used over the years in America and England [43]. Taken together, EB has shown the characteristics of low toxicity, high safety, low adverse effects and good tolerance. Considering that blocking $I_{\mathrm{NaL}}$ may be a promising approach for AF treatment, EB can potentially be developed as a potent and effective therapeutic agent for the prevention and treatment of AF.

Last but not least, the biggest highlight of our study is that we are the first to discover that EB has a selective inhibitory effect on
$I_{\mathrm{NaL}}$ rather than the other ion channels in atrial myocytes and this study illuminates the underlying mechanisms of EB on anti-AF actions. The following limitations of this study should be noted. First, the animal model of AF in this study, which is induced by the $I_{\text {NaL }}$ channel opener ATX II, cannot completely imitate the occurrence of the pathological state of AF in organisms because the pathogenesis of AF is very complicated. Second, we only explored the anti-AF effects of EB from the perspective of cardiac ion channels. There may be other potential mechanisms of EB against $A F$ that remain unknown.

In summary, our findings prove that EB exerts selective $I_{\mathrm{NaL}}$ inhibition characteristics. Suppression of $I_{\mathrm{NaL}}$ is the principle underlying electrophysiological mechanism of the anti-AF effects of $E B$ in rabbit heart models, which puts forward a pharmacological basis for new clinical applications of EB in the near future. 


\section{ACKNOWLEDGEMENTS}

This research was supported by the National Natural Science Foundation of China (No. 81670302)

\section{AUTHOR CONTRIBUTIONS}

PPZ and JHM contributed to the conception and design of the research. PPZ, ZFG, and PHZ carried out the experiments. PPZ, LS, ZPL, ZFZ, YZJ, and ZZC performed the data acquisition and analyzed the data. PPZ wrote the paper. JHM reviewed and critically revised the paper. All authors reviewed the paper, including the final submitted version.

\section{ADDITIONAL INFORMATION}

Competing interests: The authors declare no competing interests.

\section{REFERENCES}

1. Jin $X$, Jiang $Y, X u e ~ G, Y u a n ~ Y, Z$ hu $H$, Zhan L, et al. Increase of late sodium current contributes to enhanced susceptibility to atrial fibrillation in diabetic mice. Eur J Pharmacol. 2019;857:172444.

2. Yadava $M$, Hughey $A B$, Crawford TC. Postoperative atrial fibrillation: incidence, mechanisms, and clinical correlates. Heart Fail Clin. 2016;12:299-308.

3. Huang L, Zhao H, Huang B, Zheng C, Peng W, Qin L. Acanthopanax senticosus: review of botany, chemistry and pharmacology. Pharmazie. 2011;66:83-97.

4. Li C, Wang X, Hu X, Fang H, Qiao S. Determination of eleutheroside B in antifatigue fraction of Acanthopanax senticosus by HPLC. Zhongguo Zhong Yao Za Zhi. 2008;33:2800-2.

5. Lee $\mathrm{CH}$, Huang $\mathrm{CW}$, Chang $\mathrm{PC}$, Shiau JP, Lin IP, Lin MY, et al. Reactive oxygen species mediate the chemopreventive effects of syringin in breast cancer cells. Phytomedicine. 2019;61:152844.

6. Cho JY, Nam KH, Kim AR, Park J, Yoo ES, Baik KU, et al. In-vitro and in-vivo immunomodulatory effects of syringin. J Pharm Pharmacol. 2001;53:1287-94.

7. Zhou Y, Cheng C, Baranenko D, Wang J, Li Y, Lu W. Effects of Acanthopanax senticosus on brain injury induced by simulated spatial radiation in mouse model based on pharmacokinetics and comparative proteomics. Int J Mol Sci. 2018;19:159.

8. Kim B, Kim MS, Hyun CK. Syringin attenuates insulin resistance via adiponectinmediated suppression of low-grade chronic inflammation and ER stress in highfat diet-fed mice. Biochem Biophys Res Commun. 2017;488:40-5.

9. Liu KY, Wu YC, Liu IM, Yu WC, Cheng JT. Release of acetylcholine by syringin, an active principle of Eleutherococcus senticosus, to raise insulin secretion in Wistar rats. Neurosci Lett. 2008:434:195-9.

10. Lau KM, Yue GG, Chan YY, Kwok HF, Gao S, Wong CW, et al. A review on the immunomodulatory activity of Acanthopanax senticosus and its active components. Chin Med. 2019;14:25.

11. Bai $Y$, Tohda C, Zhu S, Hattori M, Komatsu K. Active components from Siberian ginseng (Eleutherococcus senticosus) for protection of amyloid beta(25-35)induced neuritic atrophy in cultured rat cortical neurons. J Nat Med. 2011;65:417-23.

12. Tohda C, Ichimura M, Bai Y, Tanaka K, Zhu S, Komatsu K. Inhibitory effects of Eleutherococcus senticosus extracts on amyloid beta(25-35)-induced neuritic atrophy and synaptic loss. J Pharmacol Sci. 2008;107:329-39.

13. Li F, Zhang N, Wu Q, Yuan Y, Yang Z, Zhou M, et al. Syringin prevents cardiac hypertrophy induced by pressure overload through the attenuation of autophagy. Int J Mol Med. 2017;39:199-207.

14. Liang Q, Yu X, Qu S, Xu H, Sui D. Acanthopanax senticosides $B$ ameliorates oxidative damage induced by hydrogen peroxide in cultured neonatal rat cardiomyocytes. Eur J Pharmacol. 2010;627:209-15.

15. Sui D, Qu S, Yu X, Chen Y, Ma X. Protective effect of ASS on myocardial ischemiareperfusion injury in rats. Zhongguo Zhong Yao Za Zhi. 2004;29:71-4.

16. Guo S, Liu Y, Lin Z, Tai S, Yin S, Liu G. Effects of eleutheroside B and eleutheroside $\mathrm{E}$ on activity of cytochrome P450 in rat liver microsomes. BMC Complement Altern Med. 2014;14:1

17. Makielski JC. Late sodium current: a mechanism for angina, heart failure, and arrhythmia. Trends Cardiovasc Med. 2016;26:115-22.

18. Saint DA. The role of the persistent $\mathrm{Na}^{+}$current during cardiac ischemia and hypoxia. J Cardiovasc Electrophysiol. 2006;17:S96-S103.
19. Xie LH, Chen F, Karagueuzian HS, Weiss JN. Oxidative-stress-induced afterdepolarizations and calmodulin kinase II signaling. Circ Res. 2009;104:79-86.

20. Guo D, Yu M, Liu Q, Cox RH, Liu T, Yan GX. Ventricular hypertrophy amplifies transmural dispersion of repolarization by preferentially increasing the late sodium current in endocardium. J Electrocardiol. 2014;47:642-8.

21. Valdivia CR, Chu WW, Pu J, Foell JD, Haworth RA, Wolff MR, et al. Increased late sodium current in myocytes from a canine heart failure model and from failing human heart. J Mol Cell Cardiol. 2005;38:475-83.

22. Blana A, Kaese S, Fortmuller L, Laakmann S, Damke D, van Bragt K, et al. Knock-in gain-of-function sodium channel mutation prolongs atrial action potentials and alters atrial vulnerability. Heart Rhythm. 2010;7:1862-9.

23. Tang $Q$, Ma J, Zhang $P$, Wan W, Kong L, Wu L. Persistent sodium current and $\mathrm{Na}^{+} /$ $\mathrm{H}^{+}$exchange contributes to the augmentation of the reverse $\mathrm{Na}^{+} / \mathrm{Ca}^{2+}$ exchange during hypoxia or acute ischemia in ventricular myocytes. Pflugers Arch. 2012:463:513-22.

24. Heijman J, Ghezelbash S, Dobrev D. Investigational antiarrhythmic agents: promising drugs in early clinical development. Expert Opin Investig Drugs. 2017;26:897-907.

25. Poulet C, Wettwer E, Grunnet M, Jespersen T, Fabritz L, Matschke K, et al. Late sodium current in human atrial cardiomyocytes from patients in sinus rhythm and atrial fibrillation. PLoS One. 2015;10:e0131432.

26. Guo D, Jenkinson S. Simultaneous assessment of compound activity on cardiac $\mathrm{Nav}_{1.5}$ peak and late currents in an automated patch clamp platform. J Pharmacol Toxicol Methods. 2018;99:106575.

27. Antzelevitch C, Burashnikov A, Sicouri S, Belardinelli L. Electrophysiologic basis for the antiarrhythmic actions of ranolazine. Heart Rhythm. 2011;8:1281-90.

28. Gong M, Zhang Z, Fragakis N, Korantzopoulos P, Letsas KP, Li G, et al. Role of ranolazine in the prevention and treatment of atrial fibrillation: a meta-analysis of randomized clinical trials. Heart Rhythm. 2017;14:3-11.

29. Song Y, Shryock JC, Belardinelli L. An increase of late sodium current induces delayed afterdepolarizations and sustained triggered activity in atrial myocytes. Am J Physiol Heart Circ Physiol. 2008;294:H2031-9.

30. Song Y, Shryock JC, Belardinelli L. A slowly inactivating sodium current contributes to spontaneous diastolic depolarization of atrial myocytes. Am J Physio Heart Circ Physiol. 2009;297:H1254-62.

31. Van Nieuwenhuyse E, Seemann G, Panfilov AV, Vandersickel N. Effects of early afterdepolarizations on excitation patterns in an accurate model of the human ventricles. PLoS One. 2017;12:e0188867.

32. Wit AL. Afterdepolarizations and triggered activity as a mechanism for clinical arrhythmias. Pacing Clin Electrophysiol. 2018;41:883-96.

33. Zhang $X, A i X$, Nakayama $H$, Chen $B$, Harris DM, Tang $M$, et al. Persistent increases in $\mathrm{Ca}^{2+}$ influx through $\mathrm{Cav}_{1.2}$ shortens action potential and causes $\mathrm{Ca}^{2+}$ overloadinduced afterdepolarizations and arrhythmias. Basic Res Cardiol. 2016;111:4.

34. Nattel S, Dobrev D. The multidimensional role of calcium in atrial fibrillation pathophysiology: mechanistic insights and therapeutic opportunities. Eur Heart J. 2012;33:1870-7.

35. Pamukcu B, Lane DA, Lip GY. The assessment of stroke and bleeding risk in atrial fibrillation: where are we now? Expert Rev Cardiovasc Ther. 2010;8:1703-10.

36. Saint DA. The cardiac persistent sodium current: an appealing therapeutic target? Br J Pharmacol. 2008;153:1133-42.

37. Michniewicz E, Mlodawska E, Lopatowska P, Tomaszuk-Kazberuk A, Malyszko J. Patients with atrial fibrillation and coronary artery disease-double trouble. Adv Med Sci. 2018;63:30-5.

38. Morita N, Sovari AA, Xie Y, Fishbein MC, Mandel WJ, Garfinkel A, et al. Increased susceptibility of aged hearts to ventricular fibrillation during oxidative stress. Am J Physiol Heart Circ Physiol. 2009;297:H1594-605.

39. Jiang W, Zeng M, Cao Z, Liu Z, Hao J, Zhang $P$, et al. Icariin, a novel blocker of sodium and calcium channels, eliminates early and delayed afterdepolarizations, as well as triggered activity, in rabbit cardiomyocytes. Front Physiol. 2017;8:342.

40. Zeng $M$, Jiang W, Tian Y, Hao J, Cao Z, Liu Z, et al. Andrographolide inhibits arrhythmias and is cardioprotective in rabbits. Oncotarget. 2017;8:61226-38.

41. Gong X, Zhang L, Jiang R, Wang C, Yin X, Wan J. Hepatoprotective effects of syringin on fulminant hepatic failure induced by $D$-galactosamine and lipopolysaccharide in mice. J Appl Toxicol. 2014;34:265-71.

42. Zang H, Yang Q, Li J. Eleutheroside B protects against acute kidney injury by activating IGF pathway. Molecules. 2019:24:3876

43. Ruhsam M, Hollingsworth PM. Authentication of eleutherococcus and rhodiola herbal supplement products in the United Kingdom. J Pharm Biomed Anal. 2018;149:403-9. 